\title{
Análisis Histológico del Proceso de Reparación en Defectos Óseos. Reconocimiento de Defectos Críticos
}

\author{
Histological Analyses of Osseous Repair Defects. Recognized of Critic Defects \\ "Henrique Duque de Miranda Chaves Netto; ",**Sergio Olate; ${ }^{* * *}$ Maria das Graças Alfonso Miranda Chaves; \\ "José Ricardo de Albergaria Barbosa \& *Renato Mazzonetto
}

CHAVES NeTTO, H. D. M.; OLATE, S.; CHAVES, M. M. G. A.; BARBOSA, A. J. R. \& MAZZONETTO, R. Análisis histológico del proceso de reparación en defectos óseos. Reconocimiento de defectos críticos. Int. J. Morphol., 27(4):1121-1127, 2009.

RESUMEN: Los procedimientos quirúrgicos que envuelven la rehabilitación de la región maxilofacial requieren frecuentemente el uso de injertos para la reconstrucción de de deformidades congénitas o adquiridas. De esta forma, defectos óseos pueden clasificarse como críticos o no críticos. En esta investigación fueron utilizados 6 canes machos realizando 2 defectos bicorticales de $8 \mathrm{~mm}$ de diámetro en la calota craneal de cada animal; el relleno de las cavidades se realizo como grupo 1 con coagulo sanguíneo y grupo 2 con hueso autógeno en partículas. A través de un an análisis histológico descriptivo se observo en el periodo de tres semanas de sacrificio que el grupo 2 fue el único en presentar regiones de aposición de nuevo tejido óseo. En el periodo de 6 semanas el grupo 2 presento partículas de hueso autógeno utilizadas para el relleno en estado de reabsorción avanzada en ausencia de los bordes nítidos entre el defecto y el hueso preexistente. De este modo se concluye que el método que auxilie en el proceso de reparación tecidual como los injertos óseos autógenos, están indicados en la recuperación de defectos críticos, iguales o mayores que 8mm.

PALABRAS CLAVE: Injerto óseo; Defectos críticos; Reparación ósea.

\section{INTRODUCCIÓN}

El hueso presenta un potencial de reparación muy elevado através de proceso dinámico de remodelación que envuelve la neoformación y la reabsorción ósea, caracterizando la casi total ausencia de cicatriz. A pesar de ello, algunos defectos óseos no presentan remodelación espontanea, necesitando factores que estimulen la reparación (Jensen et al., 2006). La velocidad de reparación del hueso es inferior a la de otros tejidos, motivo por el cual también en algunos casos es necesario la utilización de materiales de reconstrucción ósea que actúen como injertos y auxilien el proceso de reparación ósea (Hing et al., 2007).

Algunos requisitos para el adecuado desarrollo de la reparación ósea incluyen el cierre primario del tejido blando (sutura), presencia de angiogénesis que permita la irrigación sanguínea de los tejidos, presencia de células mesenquimales no diferenciadas, mantención adecuada del lecho quirúrgico y estabilidad de la región en reparación junto al material instalado (si fuesen utilizados injertos) (Wang \& Boyapati, 2006).

La forma física del material injertado influye de forma significativa en el proceso de neoformación ósea. Injertos en forma de partículas presentan una penetración facilitada por células y vasos sanguíneos, transformándose en un proceso de reparación más rápida que los injertos en las formas de bloque; la propia estructura cortical de este ultimo presenta una barrera física para la penetración de células (Moioli et al., 2008). Debido a que la formación de vasos sanguíneos ocurre de forma centrípeta, es decir, desde la periferia hacia el centro del defecto, los injertos en bloque también presentan menos estructura vascular en su región central al ser comparados con los injertos en partículas (Nishimura et al., 2004). El tipo de defecto óseo define en gran parte la forma física del injerto a ser utilizado, intentando un posicionamiento adecuado junto a la disminución de espacios entre el injerto y el lecho receptor (Nishimura et al.).

\footnotetext{
* Departamento de Diagnostico Oral, Facultad de Odontología de Piracicaba, Universidad Estadual de Campinas, Brasil.

** Departamento de Odontología Integral, Facultad de Medicina, Universidad de La Frontera, Chile.

**** Departamento de Clínica Odontológica, Facultad de Odontología, Universidad Federal de Juiz de Fora, Brasil.
} 
El injerto autógeno (hueso obtenido del propio receptor) es considerado el patrón oro en las reconstrucciones óseas, puesto que presenta las propiedades de osteoinducción, osteogénesis y osteoconducción, siendo su principal desventaja el hecho de necesitar un sitio donante, aumentando la morbilidad del procedimiento (Kübler et al., 2004).

Otra arista del asunto está en el hecho de que el sitio receptor debe ser preparado para recibir el injerto óseo ya que una parte importante de las células osteoprogenitoras vienen de esta región; además, buena parte de los osteocitos son inviables después de poco tiempo de realizado el injerto (De Boever \& De Boever, 2005). Durante la fase de remodelado del injerto óseo, las características mecánicas del sitio receptor ejercen una influencia importante, principalmente cuando las fuerzas excesivas actúan sobre el material injertado, siendo un problema relevante y común en las reconstrucciones óseas (Tong \& Buchman, 2000).

De esta forma, factores asociados al proceso de reparación ósea incluyen el tipo de defecto óseo y tipo de injerto (inlay o de cavidad y onlay o de sobreposición), existencia de fuerzas externas, estabilidad del injerto, existencia de periostio y revascularización de la región (Link et al., 2008). Cuando el defecto es inlay, la dimensión del defecto óseo presenta influencia significativa en la reparación del mismo. Son denominados defectos críticos a aquellos defectos donde el organismo no consigue promover el reparo tecidual de tejido óseo formándose, básicamente, un tejido cicatricial y son llamados defectos no críticos a los que el organismo es capaz de promover la reparación ósea integral sin métodos de auxilio para la reparación (Serra e Silva et al., 2006).

El objetivo de esta investigación es comparar a través del análisis histológico descriptivo, las diferencias existentes en el proceso de reparación ósea de defectos confeccionados en calotas cranianas de canes, utilizando el coagulo y el injerto autógeno en forma de partículas para identificar el grado de reparación entre estos dos métodos terapéuticos.

\section{MATERIAL Y MÉTODO}

Se diseñó un estudio experimental descriptivo en una muestra de 6 canes machos adultos de $15 \mathrm{~kg}$ aproximadamente. Este trabajo fue aprobado por la Comisión de Ética en Experimentación Animal de la Universidad Estadual de Campinas (CEEA)-IB-UNICAMP con el protocolo número 1343-1.

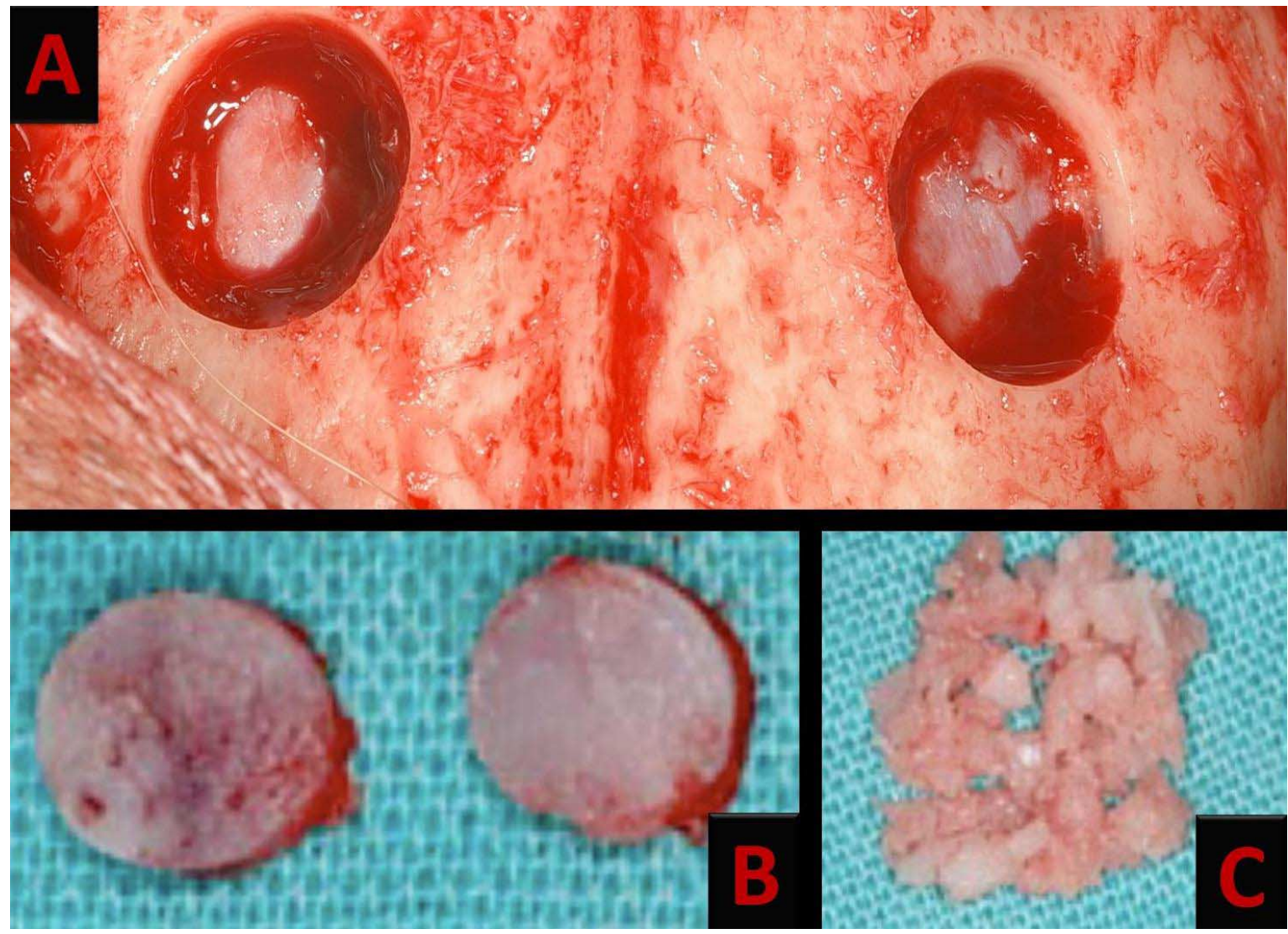

Fig. 1. A. Cavidades (defectos) confeccionadas en las regiones parietales derecha e izquierda, manteniendo la integridad de la duramadre. B. Fragmentos óseos removidos del defecto. C. Partículas óseas después de la trituración de ambos bloques. 
Procedimientos quirúrgicos. Treinta minutos antes del procedimiento, los animales recibieron profilaxis antibiótica con benzilpenicilina benzatica $(0,1 \mathrm{ml} / \mathrm{kg})$ y la aplicación del corticoide dexametasona $(0,5 \mathrm{mg} / \mathrm{kg})$, ambos por vía intramuscular. La sedación de los animales fue con el inductor anestésico cloridrato de ketamina $(0,15 \mathrm{ml} / \mathrm{kg})$, por vía intramuscular, para finalmente ser sometidos a anestesia general con inyección endovenosa de pentobarbital sódico $3 \%(30 \mathrm{mg} / \mathrm{kg})$

Después de realizar la antisepsia de rutina, fue ejecutada una incisión lineal hasta periostio para exponer la calota craniana de los animales. En ellas fueron creados dos defectos óseos con trefina de $8 \mathrm{~mm}$ de diámetro, montada en motor de baja velocidad a $1000 \mathrm{rpm}$; posteriormente fue realizado el clivaje de los fragmentos óseos hasta presentar exposición de dura madre (Fig. 1). Los fragmentos óseos removidos fueron triturados en una maquina particuladora de hueso obteniendo partículas de entre 0,5 y $2 \mathrm{~mm}$, presentando mayoritariamente partículas de tamaño menor. Después de su hidratación con suero fisiológico al 0,9\%, las partículas óseas fueron utilizadas para completar uno de los dos defectos, cubriéndolo completamente y compactándolo con instrumentos quirúrgicos y gasa seca; este defecto fue denominado grupo 2; el segundo defecto fue mantenido solo con el coágulo sanguíneo producido durante la intervención quirúrgica; este grupo se denominó grupo 1.

Finalmente, el sitio quirúrgico fue cerrado con suturas simples en tres planos utilizando suturas absorbibles y no absorbibles (vicryl 4-0, poliglactina 910).

Sacrificio de los Animales. Los animales fueron aleatoriamente divididos en dos grupos correspondiendo los dos periodos de sacrificio del estudio; el primer grupo fue sacrificado a las 3 semanas de la intervención quirúrgica y el segundo grupo a las 6 semanas post-quirúrgicas. Para este procedimiento fue realizada la sobredosis de cloro de potasio $(19,1 \%)$ por vía endovenosa; posteriormente se realizó la ostectomía para la remoción de la calota craneana con fresas 702 en pieza de alta rotación (400.000 rpm) e irrigación con suero fisiológico al $0,9 \%$ con un margen de seguridad de $5 \mathrm{~mm}$ desde la periferia del defecto óseo.

Análisis Histológico. La mantención de la pieza y confección de laminas histológicas se desarrollo mediante técnicas histológicas de rutina utilizando la tinción de hematoxilinaeosina (HE). El análisis descriptivo estudió los patrones de regeneración ósea, como presencia de reacción inflamatoria y presencia de tejido conectivo, intentando establecer una secuencia de eventos de la reparación ósea. De esta forma, los fenómenos de necrosis, hemorragia, actividad osteoclástica y osteoblástica y presencia del material injertado fueron estudiados tanto en la periferia del defecto como en el centro del mismo, empleando microscopia de luz en aumentos de $50 \mathrm{X}$ y $100 \mathrm{X}$.

\section{RESULTADOS}

Sacrificio a las 3 semanas. En el grupo 1, que corresponde a los defectos con coagulo, se observo tejido conectivo en casi la totalidad del defecto creado, la periferia estaba bien delimitada caracterizando al hueso preexistente la presencia de dos corticales nítidas. La región de la periferia también mostraba áreas de remodelación con reabsorción y aposición ósea. Entre el tejido conectivo neoformado fue posible identificar la presencia de un discreto proceso inflamatorio y algunos vasos sanguíneos. No se observo tejido óseo neoformado (Fig. 2).

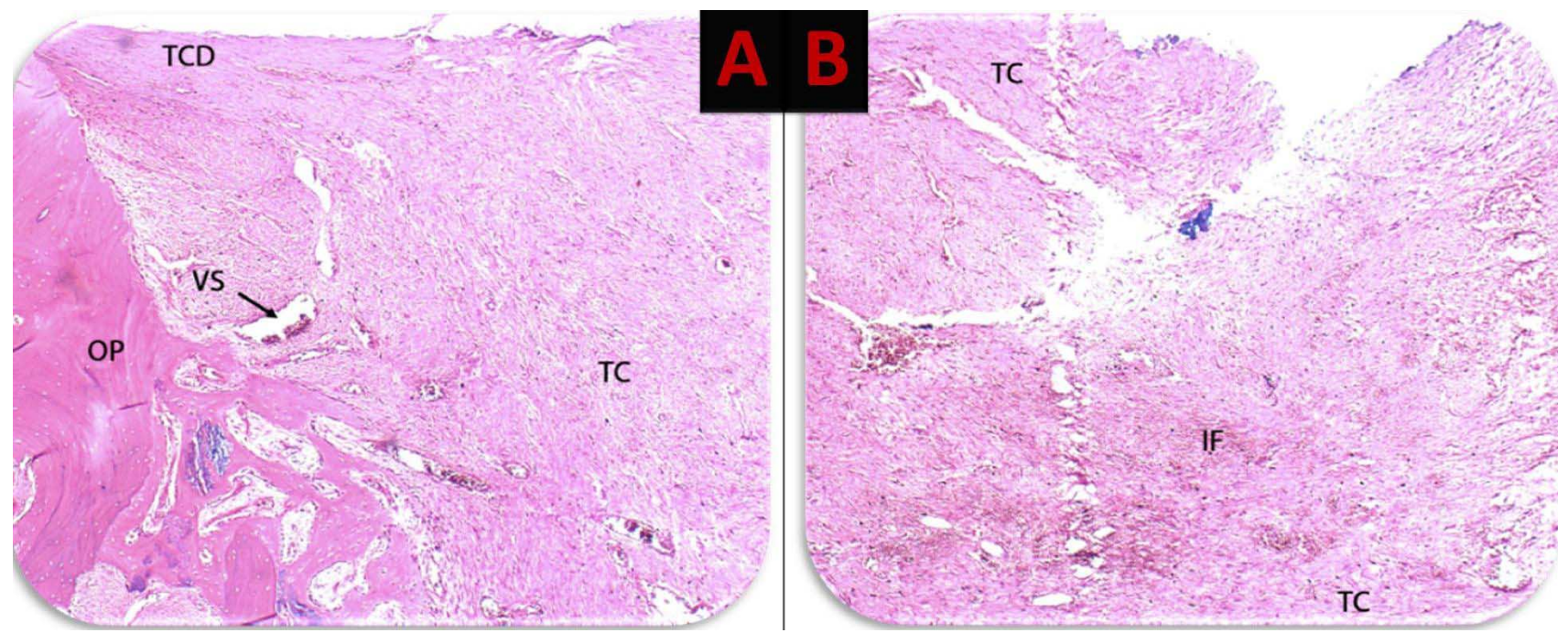

Fig. 2. Fotomicroscopia del grupo 1 después de 3 semanas de realizados los procedimientos en la calota craniana (HE; A.10x, B.20x). OP- hueso preexistente, VS- vaso sanguíneo, TC- tejido conectivo, TCD- tejido conectivo denso, IF- infiltrado inflamatorio. 
El grupo 2, de defectos rellenados con hueso autógeno en partículas presento un límite definido entre hueso preexistente y el defecto óseo. Los márgenes presentaron áreas de remodelación y neoformación ósea en dirección al centro del defecto, caracterizando un proceso de formación ósea centrípeta. Se observo también la interposición de tejido conectivo entre las trabéculas óseas neoformadas junto a áreas de angiogénesis. Se identifico un estado más avanzado de reparación ósea al ser comparado con el defecto sin injerto, estableciéndose un proceso de cicatrización por substitución de tejidos (Fig. 3). Hubo una tendencia a la formación ósea en dirección centrípeta con la presencia de fragmentos de hueso necrótico remanente (Fig. 4), en algunas áreas hubo menos reacción inflamatoria al ser comparado con el defecto sin injerto (Tabla I).

Sacrificio a las 6 semanas. En el grupo 1 (coagulo) la región límite entre el hueso preexistente y el hueso neoformado se identifico nuevamente. El hueso preexistente presento nuevamente las dos corticales definidas y el hueso esponjoso formado por tejido conectivo de buena celularidad y vascularización. Junto a los márgenes de la cavidad formada se observo remodelación del hueso preexistente y hueso neoformado en dirección centrípeta. En la porción central se observo tejido conectivo fibroso entre algunas trabéculas óseas neoformadas (Fig. 5).

En el grupo 2 (injerto de hueso autógeno), se observo un relleno casi integral de la cavidad quirúrgica, con presencia de algunas áreas de tejido conectivo fibroso y tejido óseo esponjoso. Los bordes del defecto se presentaron limitadas; en el interior del tejido óseo neoformado se visualizo algunas partículas del injerto junto a nuevos vasos sanguíneos. Se verifico claramente un estado más avanzado de reparación ósea con un crecimiento centrípeto (Fig. 6).

Tabla I. Resumen del análisis histológico descriptivo en defectos óseos de 6 animales estudiados en dos periodos de sacrificios (3Ssacrificio de 3 semanas; $6 \mathrm{~S}$ - sacrificio de 6 semanas).

\begin{tabular}{|c|c|c|c|c|c|c|c|}
\hline & $\begin{array}{c}\text { Tejido } \\
\text { conectivo }\end{array}$ & $\begin{array}{c}\text { Infiltrado } \\
\text { inflamatorio }\end{array}$ & Aposición ósea & $\begin{array}{l}\text { Tejido óseo } \\
\text { neoformado }\end{array}$ & $\begin{array}{l}\text { Material } \\
\text { injertado }\end{array}$ & $\begin{array}{c}\text { Vaso } \\
\text { sanguíneo }\end{array}$ & $\begin{array}{l}\text { Periferia } \\
\text { defecto }\end{array}$ \\
\hline Defecto con coágulo (3S) & Presente & Discreto & Ausente & Ausente & Inexistente & Presente & Presente \\
\hline Defecto con injerto (3S) & Presente & Discreto & Presente & Presente & Presente & Presente & Presente \\
\hline Defecto con coágulo (6S) & Presente & Discreto & Ausente & Presente & Inexistente & Presente & Presente \\
\hline Defecto con injerto (6S) & Presente & Discreto & Presente & Presente & Presente & Presente & Ausente \\
\hline
\end{tabular}

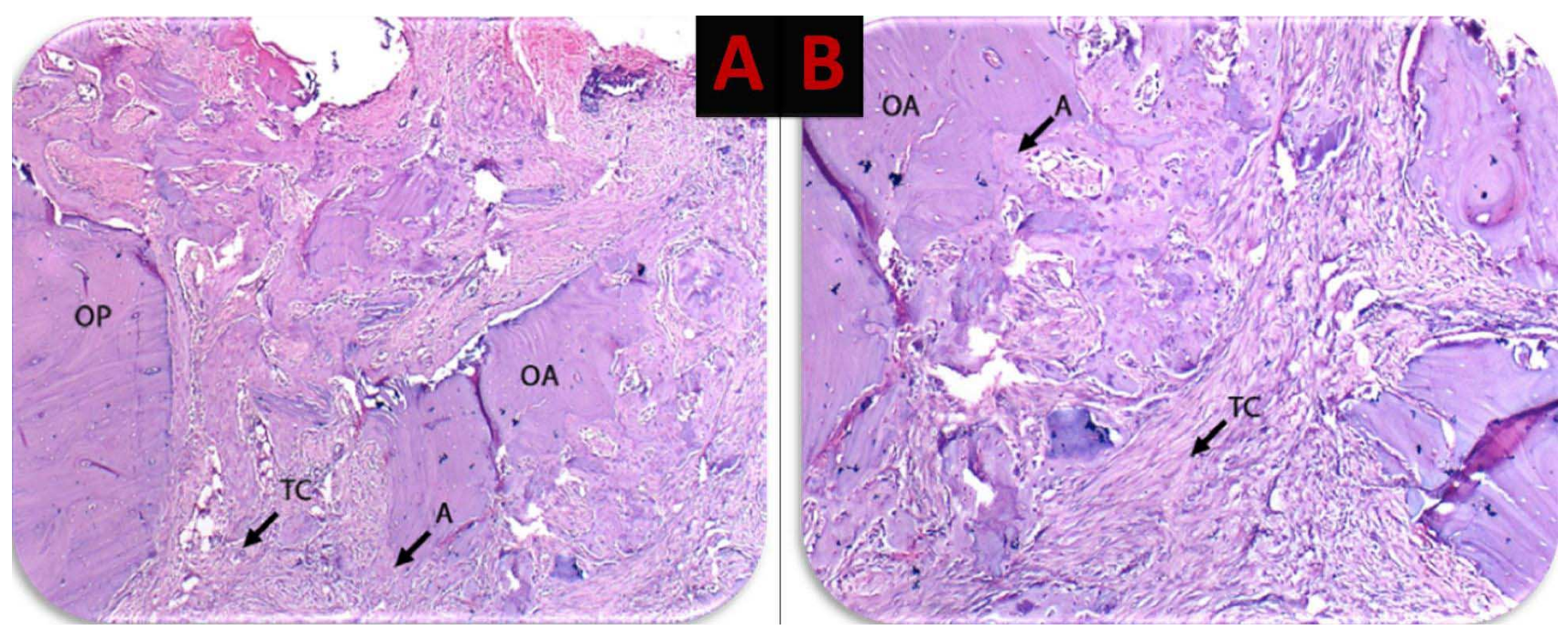

Fig. 3. Fotomicroscopia del grupo 2 en el primer sacrificio de 3 semanas (HE; A.10x, B.20x). A- aposición de nuevo hueso, OA- injerto de hueso autógeno, TC- tejido conectivo. 


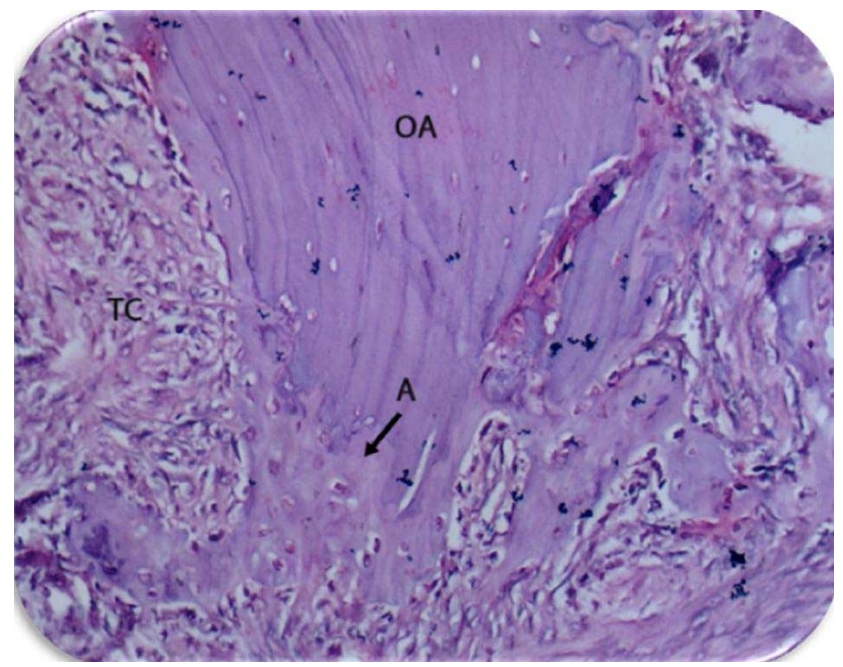

Fig. 4. Fotomicroscopia del grupo 2 despues de 3 semanas del sacrificio (HE; 40x). A-aposición de nuevo hueso, OAinjerto de hueso autógeno, TC- tejido conectivo.

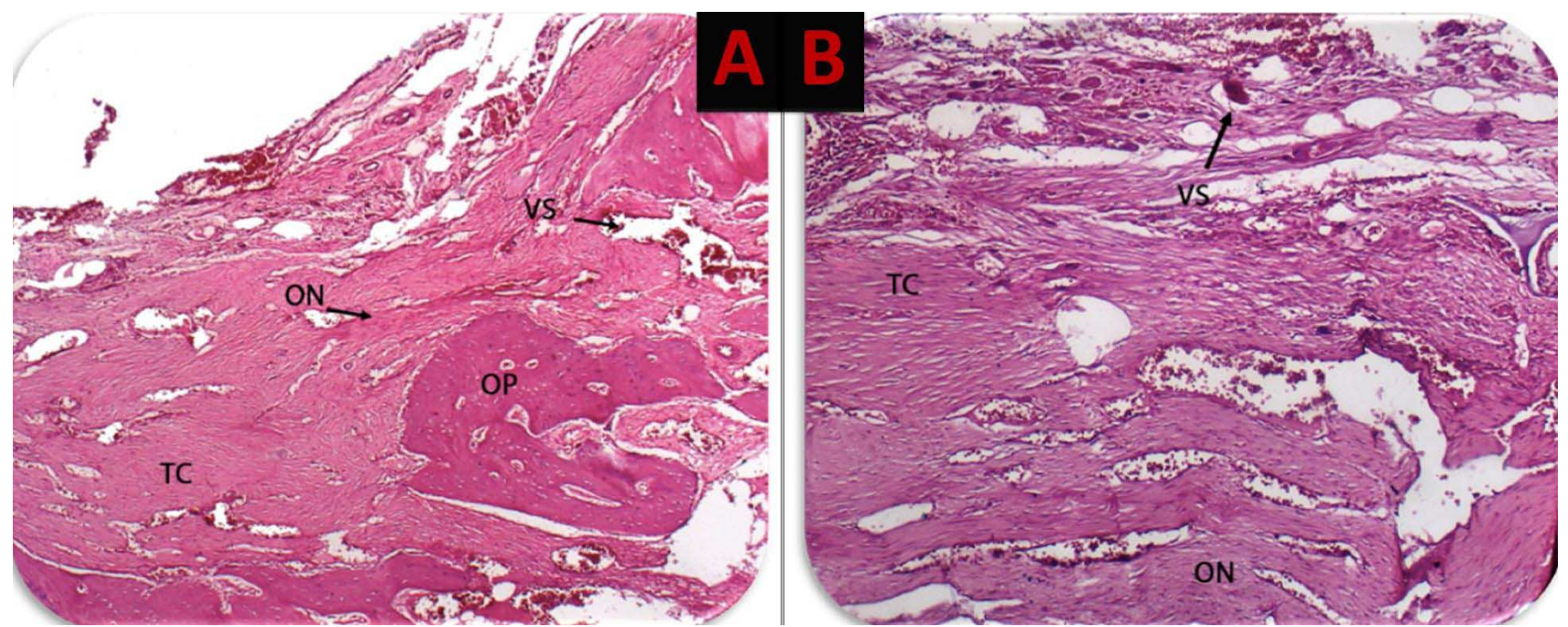

Fig. 5. Fotomicroscopia del grupo 1 el segundo periodo de sacrificio de 6 semanas (HE; A.10x, B.20x). OP- tejido óseo preexistente, ONtejido óseo neoformado, TC- tejido conectivo, VS- vaso sanguíneo.

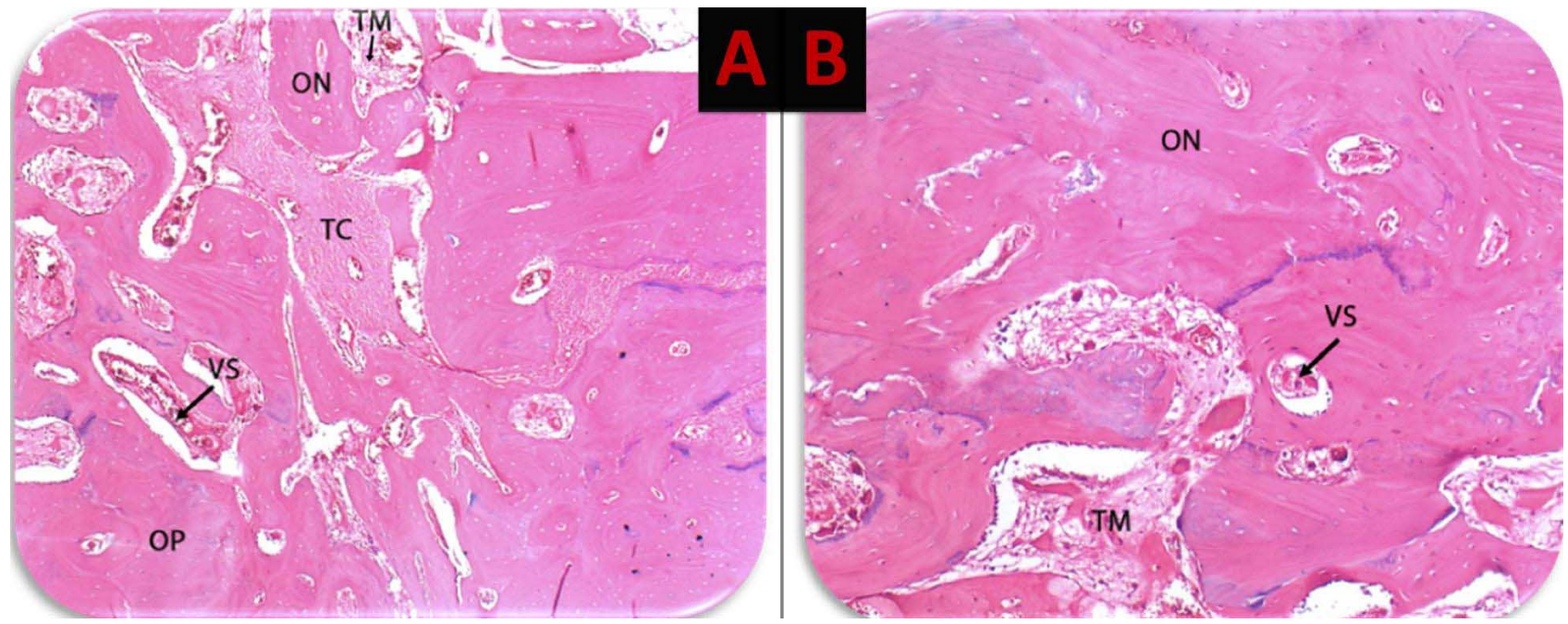

Fig. 6. Fotomicroscopia del grupo 2 a las 6 semanas del sacrificio de los animales (HE; A.10x, B.20x). ON- tejido óseo neoformado, TCtejido conectivo, VS- vaso sanguíneo, TM: tejido óseo esponjoso. 


\section{DISCUSIÓN}

El presente estudio es capaz de reportar un proceso de reparación ósea más rápida en defectos rellenados con hueso en partículas al ser comparados con los rellenos con coagulo, lo que está de acuerdo con otros resultados encontrados en la literatura internacional (Haas et al., 2002; Laureano-Filho et al., 2007).

Turner (2001) estudió el proceso de reparación ósea en diferentes modelos animales (primates, canes, gatos, ratones, conejos y minicerdos), observando que la velocidad de la reparación ósea en el humano era más próxima al de los perros con una relación de 1:3 (hombre: can). De esta forma, los periodos de sacrificio de 3 a 6 semanas corresponderían a fases de reparación ósea de 1 y 2 mes en el humano.

Una de las indicaciones para el uso de injertos óseos está representado por la presencia de defectos críticos, puesto que estos no consiguen una reparación completamente autónoma o sin ayuda de técnicas reconstructivas (Callan \& Rohrer, 1993). Estudios anteriores señalaron que defectos de $8 \mathrm{~mm}$ se presentaban como defectos no críticos (Hollinger \& Kleinschmidt, 1990; Klüppel, 2007). A pesar de ello, en este estudio fue posible observar que los defectos confeccionados en las calotas craneanas no presentaron reparación ósea espontanea después de 6 semanas de análisis, pre- sentando una elevada cantidad de tejido conectivo en la región central del defecto. De esta forma, defectos iguales o superiores a $8 \mathrm{~mm}$ de diámetro deberían ser considerados como defectos críticos, necesitando técnicas reconstructivas como la instalación de injertos para obtener la reparación integral del sitio óseo defectuoso.

El hueso autógeno es considerado el patrón de oro en las técnicas reconstructivas. Diferentes estudios ratifican la capacidad de estimular positivamente el proceso de reparación, permitiendo la aceleración de la secuencia biológica y optimas cualidades tisulares al final del proceso (Tong \& Buchman; Wang \& Boyapati; Hing et al.). Durante el estudio histológico se observo que las cavidades con injerto óseo presentaron un proceso de reparación más avanzado, observándose regiones de aposición ósea en la periferia de los defectos a las 3 semanas; a las 6 semanas fue menos visible la diferencia en el margen del defecto, prueba de la existencia de reparación ósea avanzada en esta región.

\section{CONCLUSIÓN}

Defectos iguales o superiores a $8 \mathrm{~mm}$ de diámetro mayor deben ser considerados como de tipo crítico. Los injertos de partículas de hueso autógeno son auxiliares del proceso de reparación ósea, siendo indicados para la reparación de defectos con tres o mas paredes.

CHAVES NeTTO, H. D. M.; OLATE, S.; CHAVES, M. M. G. A.; BARBOSA, A. J. R. \& MAZZONETTO, R. Histological analyses of osseous repair defects. Recognized of critic defects.Int. J. Morphol., 27(4):1121-1127, 2009.

SUMMARY: Surgical procedures involving maxillofacial region frequently require bone grafting to reconstruct the congenital or acquired defects, as well to aesthetic. The bone defect can critical or non-critical. To perform the present studied were used 8 dogs, males. It was performed 2 bicortical defects having $8 \mathrm{~mm}$ of diameter on the calvarium of each animal. The cavities were filled up thru the following way: group 1 - blood clot, group 2 - particulate autogenous bone graft. Thru the descriptive radiologic and histological analysis, it was observed on 3 weeks period that The group 2 was the only one that presented new bone apposition. On the 6 weeks sacrifice period. The group 2 was the only one that showed advanced resorption stage of the bone grafts particles used for fulfillment being, also the only one that showed periphery of the defects without limit. On this way, it may be conclude that bone defects over $8 \mathrm{~mm}$ can be considered Critical, being necessary some method to help tissue repair, as well as, autogenous bone grafts works well when helping this regeneration process, being indicated to assist bone repair like this performed on this study.

Key words: Bone grafts; Critical defect; Osseous repair.

\section{REFERENCIAS BIBLIOGRÁFICAS}

Callan, D. P. \& Rohrer, M. D. Use of bovine derived hydroxiapatite in the treatment of edentulous ridge defects: a human clinical and histologic case report. $J$. Periodontol., 64:575-82, 1993.

De Boever, A. L. \& De Boever, J. A. Guided bone regeneration around non-submerged implants in narrow alveolar ridges: a prospective long-term clinical study. Clin. Oral Impl. Res., 16:549-56, 2005.

Haas, R.; Haidvogl, D.; Donath, K. \& Watzek, G. Freezedried homogeneous and heterogeneous bone for sinus 
CHAVES NETTO, H. D. M.; OLATE, S.; CHAVES, M. M. G. A.; BARBOSA, A. J. R. \& MAZZONETTO, R. Análisis histológico del proceso de reparación en defectos óseos. Reconocimiento de defectos críticos. Int. J. Morphol., 27(4):1121-1127, 2009.

augmentation in sheep: Part I - Histological findings. Clin. Oral Impl. Res. , 13:396-404, 2002.

Hing, K. A.; Wilson, L. F. \& Buckland, T. Comparative performance of three ceramic bone graft substitutes. Spine J., 7(4):457-90, 2007.

Hollinger, J. O. \& Kleinschmidt, J. C. The critical size defect as an experimental model to test bone repair materials. J. Craniofac. Surg., 1(1):60-8, 1990.

Jensen, S. S.; Broggini, N.; Hjorting-Hansen, E.; Schenk, R. $\&$ Buser, D. Bone healing and graft resorption of autograft, anorganic bovine bone $\beta$-tricalcium phosphate. A histologic and histomorphometric study in the mandible of minipigs. Clin. Oral Impl. Res., 17:237-43, 2006.

Klüppel, L. E. Influência dos diferentes tamanhos de partículas da matriz óssea bovina anorgânica no processo de reparo ósseo. Análise histológica e radiográfica de defeitos criados cirurgicamente em calvária de coelhos. Piracicaba, FOP/UNICAMP, 2007.

Kübler, A.; Neugebauer, J.; Oh, J.; Scheer, M. \& Zöller, J., E. Growth and proliferation of human osteoblasts in different bone graft substitutes. An in vitro study. Implant Dent., 13:171-9, 2004.

Laureano-Filho, J. R.; Branco, B. L. C. \& Andrade, E. S. S.; Albergaria-Barbosa, J. R. Comparação histological entre o osso desmineralizado e polímero de mamona sobre a regeneração óssea. Rev. Bras. Otorrinolaringol., 73(2):123-45, 2007.

Link, D.; Van den Dolder, J.; van den Beucken, J.; Wolke, J.; Mikos, A. \& Jansen, J. Bone response and mechanical strength of rabbit femoral defects filled with injectable CaP cements containing TGF-b1 loaded gelatin microparticles. Biomaterials, 29:675-82, 2008.

Moioli, E.; Clark, P.; Summer, C. \& Mao, J. Autologous stem cell regeneration in craniosynostosis. Bone, 42:332-40, 2008.

Nishimura, I.; Shimizu, Y. \& Ooya, K. Effects of cortical bone perforation on experimental guided bone regeneration. Clin. Oral Impl. Res., 15:293-300, 2004.

Serra e Silva, F.; Albergaria-Barbosa, J. R. \& Mazzonetto, $\mathrm{R}$. Clinical evaluation of association of bovine organic osseous matrix and bovine bone morphogenetic protein versus autogenous bone graft in sinus floor augmentation.
J. Oral Maxillofac. Surg., 64:931-5, 2006.

Tong, L. \& Buchman, S. R. Facial bone grafts: contemporary science and thought. J. Craniomaxillofac. Trauma, 6:3141, 2000.

Turner, A. S. Animal models of osteoporosis - Necessity and limitations. Eur. Cells Mat., 1:66-81, 2001.

Wang, H. L. \& Boyapati, L. "PASS" Principles for Predictable Bone Regeneration. Implant Dent., 15(1):1$17,2006$.

Dirección para correspondencia

Prof. Dr. Renato Mazzonetto

Av. Limeira 901

Caixa Postal 52

CEP 13414-903

Piracicaba - SP

BRASIL

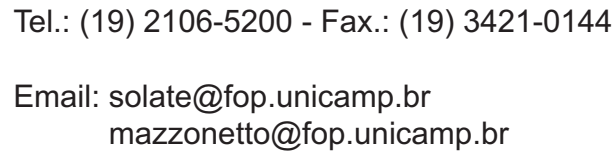

Recibido : 07-07-2009

Aceptado: 22-09-2009 